\title{
Impact of air pollution on hospital patients admitted with ST- and non-ST-segment elevation myocardial infarction in heavily polluted cities within the European Union
}

Paweł E. Buszman ${ }^{1,2}$, Kamil Derbisz ${ }^{1}$, Przemysław Kwasiborski ${ }^{1}$, Patrycja Chrząszcz ${ }^{1}$, Magdalena Mularska ${ }^{1}$, Dominika Baron ${ }^{1}$, Anna Sobieszek ${ }^{1}$, Artur Mendyk ${ }^{1}$, Paweł Skoczylas $^{3}$, Marek Cisowski ${ }^{1}$, Piotr P. Buszman ${ }^{1,2}$, Krzysztof Milewski ${ }^{1,4}$

${ }^{1}$ Center for Cardiovascular Research and Development, American Heart of Poland, Katowice, Poland ${ }^{2}$ Andrzej Frycz Modrzewski Krakow University, Faculty of Medicine and Health Sciences, Krakow, Poland ${ }^{3}$ University of Social Sciences, Poland

${ }^{4}$ The Jerzy Kukuczka Academy of Physical Education, Katowice, Poland

\begin{abstract}
Background: Air pollution triggered diseases have become a leading health problem worldwide. The main adverse effects of air pollutants on human health are related to the cardiovascular system and particularly show an increasing prevalence of myocardial infarct and stroke. The aim of the study was to evaluate the influence of main air pollutants on non-ST-segment elevation myocardial infarction (NSTEMI) and ST-segment elevation myocardial infarction (STEMI) admissions to local interventional cardiology centers.

Methods: Between 2014 and 2015, a multicenter registry of 1957 patients with acute myocardial infarction (STEMI, NSTEMI) admitted to interventional cardiology departments in three Polish cities were under investigation. The air pollution (PM2.5, PM10, NO2, SO2, O3) and weather conditions (temperature, barometric pressure, humidity) data for each city were collected as daily averages. The case-crossover design and conditional logistic regression were used to explore the association between acute myocardial infarctions and short-term air pollution exposure.

Results: Occurrence of NSTEMI on the day of air pollution was triggered by PM2.5 (OR $=1.099$, $p=0.01)$ and $P M 10(O R=1.078, p=0.03)$. On the following day after the air pollution was recorded, NSTEMI was induced by: PM2.5 (OR $=1.093, p=0.025), P M 10(O R=1.077, p=0.025)$ and $S O 2(O R=1.522, p=0.009)$. For STEMI, events that occurred on the day in which air pollution was triggered by: PM2.5 (OR = 1.197, $p<0.001), P M 10(O R=1.163, p<0.001)$, SO2 (OR = 1.670, $p=0.001)$ and NO2 (OR =1.287, $p=0.011)$. On the following day after air pollution was recorded, STEMI was induced by: PM2.5 (OR $=1.172, p<0.001), P M 10$ (OR $=1.131, p=0.001)$, SO2 $(O R=1.550, p=0.005)$ and NO2 (OR = 1.265, $p=0.02)$. None of the weather conditions indicated were statistically significant for acute myocardial infarction occurrence.

Conclusions: The most important pollutants triggering acute myocardial infarction occurrence in the population of southern Poland, both on the day of air pollution and the following day are particulate matters (PM2.5, PM10) and gaseous pollutants including NO2 and SO2. These pollutants should be regarded as modifiable risk factors and thus, their reduction is a priority in order to decrease total morbidity and mortality in Poland. (Cardiol J 2020; 27, 5: 541-547)
\end{abstract}

Key words: air pollution, myocardial infarction, non-ST-segment elevation myocardial infarction (NSTEMI), ST-segment elevation myocardial infarction (STEMI)

Address for correspondence: Paweł E. Buszman, MD, PhD, Center For Cardiovascular Research and Development, American Heart of Poland, ul. Czajek 41, 40-761 Katowice, Poland, tel: +48 3225102 11, fax: +48 322510211 , e-mail: pawel.buszman@ahop.pl

Received: 24.09.2018 Accepted: 7.11.2018 


\section{Introduction}

Air pollution triggered diseases have become a leading problem both in well-developed and for emerging economy countries. According to The World Health Organization 3.7 million deaths per year occur from exposure to outdoor air pollution [1]. What is more, $72 \%$ of air pollution-related premature deaths were due to ischemic heart disease and strokes [2]. This confirms, that the cardiovascular system is one of the most susceptible human body systems affected by ambient air pollution.

Outdoor air pollution is particularly driven by industry, transport (especially diesel engines) and other combustion processes such as heating and power generation devices. It consists of particulate matter (PMs) and gaseous pollutants - carbon monoxide (CO), sulfur dioxide (SO2), nitrogen dioxide (NO2) and ozone (O3). PMs can be further divided according to their diameter to PM10 $(\leq 10 \mu \mathrm{m})$, PM2.5 $(\leq 2.5 \mu \mathrm{m})$.

Previous studies have explored the association between acute myocardial infarctions (AMIs) and air pollution. The results were conflicting. Some of them have shown an association between AMIs and some air pollutants, especially PM2.5, PM10, $\mathrm{SO} 2$ and NO2 [3]. The main pathology mechanism of air pollution affecting the cardiovascular system includes systemic and local oxidative stress and inflammation that triggers endothelial dysfunction, platelet hyperreactivity and impaired vascular fibrinolytic function [4]. The local mechanism is caused by gases and soluble components of particulate matter, especially those with the smallest diameter which can easily cross the pulmonary epithelium and get into the blood stream. The systemic pathway is activated by pulmonary inflammation and oxidative stress, which was confirmed by the increasing level of pro inflammatory cytokines in the animal and human studies after short exposure to air pollutants [5]. Moreover, in experimental studies the autonomic imbalance favoring sympathetic activation leads to arrhythmia, vasoconstriction and hypertension [6].

All of these mechanisms may accelerate atherosclerosis, plaque instability and promote atherothrombosis, resulting in AMI and sudden death in short, as well as long-term observation. From an epidemiological point of view, the air pollutants are of important meaning as they can be qualified as modifiable risk factors of myocardial infarct and the prevention of air pollution should be included in national programs of cardiovascular disease prevention.
On the other hand, some non-modifiable factors have been considered to be triggering AMIs such as weather conditions [7]. Among meteorological variables, temperature [8] and barometric pressure [9] have been found to be prominently associated with myocardial infarction.

Thus, it is of great importance to further investigate the influence of major air pollutants and meteorological variables which effect health status. The evaluation may be especially valuable when performed in the most polluted areas where the scale of affect seems to have the strongest effect and may be more easily measured. It is also important to measure the effect in large enough and similar populations, based on serial observations that take into account not only polluted days but also refer to the periods of normal weather conditions.

Despite having a well-developed structure for optimal AMI treatment, Poland has been qualified as one of the European Union countries with highest rate of MI, stroke event rate and cardiovascular mortality. At the same time, Poland is one of the most air polluted countries in Europe, where fossil fuel is a major source of energy and the role of air pollution is underestimated [10]. This situation has prompted this study to perform an analysis that can evaluate the influences of all commonly measured air pollutants and weather condition parameters, separately on non-ST-segment elevation myocardial infarction (NSTEMI), ST-segment elevation myocardial infarction (STEMI) occurrence based on data selected from three typical, Polish, small and medium sized industrial cities.

\section{Methods}

\section{Database}

This study draws from a multicentre registry of AMI of three American Heart of Poland centers located in industrial cities in southern Poland: Kedzierzyn-Kozle (fifty-eight thousand inhabitants), Bielsko-Biala (one hundred seventy thousand inhabitants) and Mielec (sixty-two thousand inhabitants). Based on recently published registries these regions have qualified as some of the most air polluted regions in Europe [11]. Data collection covered a period from January 2014 to December 2015 from the regions of Bielsko-Biala, July 2014 to December 2015 from KedzierzynKozle and January 2015 to December 2015 from Mielec. The differences in these analyzed periods between centers are the result of different onset of air-quality monitoring in each city. All reported 
Table 1. Air quality in selected cities [11].

\begin{tabular}{lccccc}
\hline Center & $\begin{array}{c}\text { Days above PM2.5 } \\
\left(25 \mu \mathrm{m} / \mathrm{m}^{3}\right) \text { limit } \\
(\% \text { of tested } \\
\text { period) }\end{array}$ & $\begin{array}{c}\text { Annual mean } \\
\text { of PM2.5 }\end{array}$ & $\begin{array}{c}\text { Days above PM10 } \\
\left(50 \mu \mathrm{m} / \mathrm{m}^{3}\right) \text { limit } \\
(\% \text { of tested } \\
\text { period) }\end{array}$ & $\begin{array}{c}\text { Annual mean } \\
\text { of PM10 }\end{array}$ & $\begin{array}{c}\text { Place in WHO } \\
\text { report }\end{array}$ \\
\hline Bielsko-Biala & 233 days (34\%) & $34 \mu \mathrm{m} / \mathrm{m}^{3}$ & 142 days $(21 \%)$ & $41 \mu \mathrm{m} / \mathrm{m}^{3}$ & 32 \\
Kedzierzyn-Kozle & 187 days (43\%) & $33 \mu \mathrm{m} / \mathrm{m}^{3}$ & 80 days $(18.5 \%)$ & $39 \mu \mathrm{m} / \mathrm{m}^{3}$ & 37 \\
Mielec & 132 days (38\%) & $31 \mu \mathrm{m} / \mathrm{m}^{3}$ & 61 days $(18 \%)$ & $42 \mu \mathrm{m} / \mathrm{m}^{3}$ & 56 \\
\hline
\end{tabular}

WHO - World Health Organization

data come from local departments of interventional cardiology, which are the only centers providing $24 / 7$ services in their regions. In the clinical data, both types of myocardial infarction admissions (STEMI and NSTEMI) were collected. The types of AMIs were established based on clinical data reported to the National Health Fund.

The air pollution and weather condition data for each city were collected as daily averages from a database audited by the Chief Inspectorate of Environmental Protection in Poland. The following parameters were assembled: PM2.5, PM10, NO2, SO2, O3, barometric pressure, temperature and humidity. The cities were selected for this study based on the most complete and accurate data from air pollution measuring stations.

In order to present daily trends in particulate matter, concentrations over the analyzed period of time and were combined with the trends in the incidence of MIs. The data was further divided into PM2.5 and PM10 consecutive thresholds in which each an increase in concentration of $10 \mu \mathrm{m} / \mathrm{m}^{3}$ was translated into a higher threshold. In this division, the daily limit for PM2.5 $\left(25 \mu \mathrm{m} / \mathrm{m}^{3}\right)$ was included in threshold 3 while the limit for PM10 $\left(50 \mu \mathrm{m} / \mathrm{m}^{3}\right)$ was in threshold 6 .

\section{Statistical analysis}

The case-crossover design was used to explore the association between each type of AMI and air pollution exposure. In this type of analysis each case provides its own control, eliminating the influence of time-independent covariates, for instance hypertension, smoking, hypercholesterolemia and others [12]. The value of each pollutant, barometric pressure, temperature and humidity during the day of MI occurrence or the previous day to MI were considered in each case. The median level of each of the above-mentioned variables from the 7 days prior to MI were taken as a control. The present study was focused on the short-term influence of each variable on NSTEMI or STEMI occurrence, and was restricted to the day of exposure (day 0) and the following day after exposure (day 1).

In statistical analysis, conditional logistic regression was used to assess the odds ratio (OR) with $95 \%$ confidence intervals $(95 \% \mathrm{CI})$. Analysis was performed for a $10 \mu \mathrm{m} / \mathrm{m}^{3}$ increase in air pollutants, $10^{\circ} \mathrm{C}$ increase in temperature, $10 \%$ increase in humidity and $10 \mathrm{mmHg}$ change in the barometric pressure. The correlation between air pollutants and weather conditions were calculated using the Spearman correlation. P value $\leq 0.05$ was considered as statistically significant.

\section{Results}

The air quality in all cities were comparable based on the latest World Health Organization (WHO) report [11] and measurements of air pollutants (Table 1). Full data on air pollution measurement were available for $89 \%$ (1462 days) over the observation time period and 1957 cases of MI were analyzed. Precise characteristics of data collected are seen in Table 2 . The reason for days missing was the lack of respective measurements of air quality due to periodic failures of local pollution measuring stations. If any measurement was missing during this period, it was excluded from study.

NSTEMI was presented during 686 days with complete, available pollution measurements and its total was 985 cases. STEMI was presented during 666 days with complete, available pollution measurements and the total number of cases was 972. Daily means of incidences in all centers were as follows: NSTEMI $0.67 \pm 0.86$ cases, STEMI $0.66 \pm 0.87$ cases and AMI's $1.33 \pm 1.24$ cases. Detailed information about daily mean incidence occurrence was separate for all cities and are represented in Table 3.

The main descriptive statistics for variables are presented in Table 4 . The correlations between variables are presented in Table 5 . The highly positive correlations were observed between PM2.5 
Cardiology Journal 2020, Vol. 27, No. 5

Table 2. Main characteristic of data collected from different centers.

\begin{tabular}{lccccc}
\hline Center & Period & $\begin{array}{c}\text { Available } \\
\text { data }(\%)\end{array}$ & $\begin{array}{c}\text { MI } \\
\text { cases }\end{array}$ & $\begin{array}{c}\text { NSTEMI } \\
\text { cases }\end{array}$ & $\begin{array}{c}\text { STEMI } \\
\text { cases }\end{array}$ \\
\hline All centers & 1644 days & 1462 days (89\%) & 1957 & 985 & 972 \\
Bielsko-Biala & $2014-2015$ (730 days) & 682 days $(93 \%)$ & 1185 & 561 & 624 \\
Kedzierzyn-Kozle & July $2014-2015$ (549 days) & 433 days (79\%) & 443 & 252 & 191 \\
Mielec & 2015 (365 days) & 347 days (95\%) & 329 & 172 & 157 \\
\hline
\end{tabular}

MI — myocardial infarction; NSTEMI — non-ST-segment elevation myocardial infarction; STEMI — ST-segment elevation myocardial infarction

Table 3. Mean daily occurrence of acute myocardial infarction.

\begin{tabular}{lccc}
\hline Center & MI daily & NSTEMI daily & STEMI daily \\
\hline All centers & $1.33 \pm 1.24$ & $0.67 \pm 0.86$ & $0.66 \pm 0.87$ \\
Bielsko-Biala & $1.73 \pm 1.35$ & $0.82 \pm 0.95$ & $0.91 \pm 0.99$ \\
Kedzierzyn-Kozle & $1.02 \pm 1.03$ & $0.58 \pm 0.77$ & $0.44 \pm 0.68$ \\
Mielec & $0.95 \pm 1.02$ & $0.49 \pm 0.74$ & $0.45 \pm 0.70$ \\
\hline
\end{tabular}

Data are shown as mean \pm standard deviation. $\mathrm{Ml}$ - myocardial infarction; NSTEMI - non-ST-segment elevation myocardial infarction; STEMI - ST-segment elevation myocardial infarction

Table 4. Descriptive statistics for each variable measured.

\begin{tabular}{lccccc}
\hline Variable & Median & Minimum & Maximum & Mean & \pm SD \\
\hline $\mathrm{PM} 2.5\left[\mu \mathrm{m} / \mathrm{m}^{3}\right]$ & 20 & 3 & 256 & 27.59 & 22.89 \\
$\mathrm{PM} 10\left[\mu \mathrm{m} / \mathrm{m}^{3}\right]$ & 27 & 5 & 260 & 35.41 & 26.26 \\
$\mathrm{SO} 2\left[\mu \mathrm{m} / \mathrm{m}^{3}\right]$ & 5 & 0.7 & 80 & 7.56 & 6.63 \\
$\mathrm{NO} 2\left[\mu \mathrm{m} / \mathrm{m}^{3}\right]$ & 16 & 3 & 69 & 17.80 & 8.55 \\
O3 $\left[\mu \mathrm{m} / \mathrm{m}^{3}\right]$ & 51 & 1 & 127 & 50.26 & 23.84 \\
Barometric pressure $[\mathrm{hPa}]$ & 987 & 932 & 1021 & 984.04 & 15.36 \\
Temperature $\left[{ }^{\circ} \mathrm{C}\right]$ & 9 & -18 & 29 & 9.64 & 8.06 \\
Humidity $[\%]$ & 78 & 31 & 99 & 77.25 & 14.21 \\
\hline
\end{tabular}

PM2.5 - particulate matter with diameter $<2.5 \mu \mathrm{m}$; PM10 - particulate matter with diameter $<10 \mu \mathrm{m}$; SO2 — sulfur dioxide; NO2 - nitrogen dioxide; $\mathrm{O} 3$ - ozone; SD — standard deviation

Table 5. Spearman correlations between variables. All statistically significant correlations are highlighted.

\begin{tabular}{lcccccccc}
\hline Variable & PM10 & PM2.5 & SO2 & NO2 & O3 $\begin{array}{c}\text { Barometric Temperature Humidity } \\
\text { pressure }\end{array}$ \\
\hline PM10 & 1.00 & 0.90 & 0.64 & 0.71 & -0.47 & 0.21 & -0.40 & 0.09 \\
PM2.5 & 0.90 & 1.00 & 0.61 & 0.65 & -0.51 & 0.21 & -0.43 & 0.16 \\
SO2 & 0.64 & 0.61 & 1.00 & 0.59 & -0.41 & -0.10 & -0.63 & 0.19 \\
NO2 & 0.71 & 0.65 & 0.59 & 1.00 & -0.60 & -0.02 & -0.38 & 0.32 \\
O3 & -0.47 & -0.51 & -0.41 & -0.60 & 1.00 & -0.18 & 0.56 & -0.64 \\
Barometric pressure & 0.21 & 0.21 & -0.10 & -0.02 & -0.18 & 1.00 & 0.12 & -0.34 \\
Temperature & -0.40 & -0.43 & -0.63 & -0.38 & 0.56 & 0.12 & 1.00 & -0.49 \\
Humidity & 0.09 & 0.16 & 0.19 & 0.32 & -0.64 & -0.34 & -0.49 & 1.00 \\
\hline
\end{tabular}

PM2.5 - particulate matter with diameter $<2.5 \mu \mathrm{m}$; PM10 - particulate matter with diameter $<10 \mu \mathrm{m}$; SO2 — sulfur dioxide; NO2 — nitrogen dioxide; $\mathrm{O} 3$ - ozone 


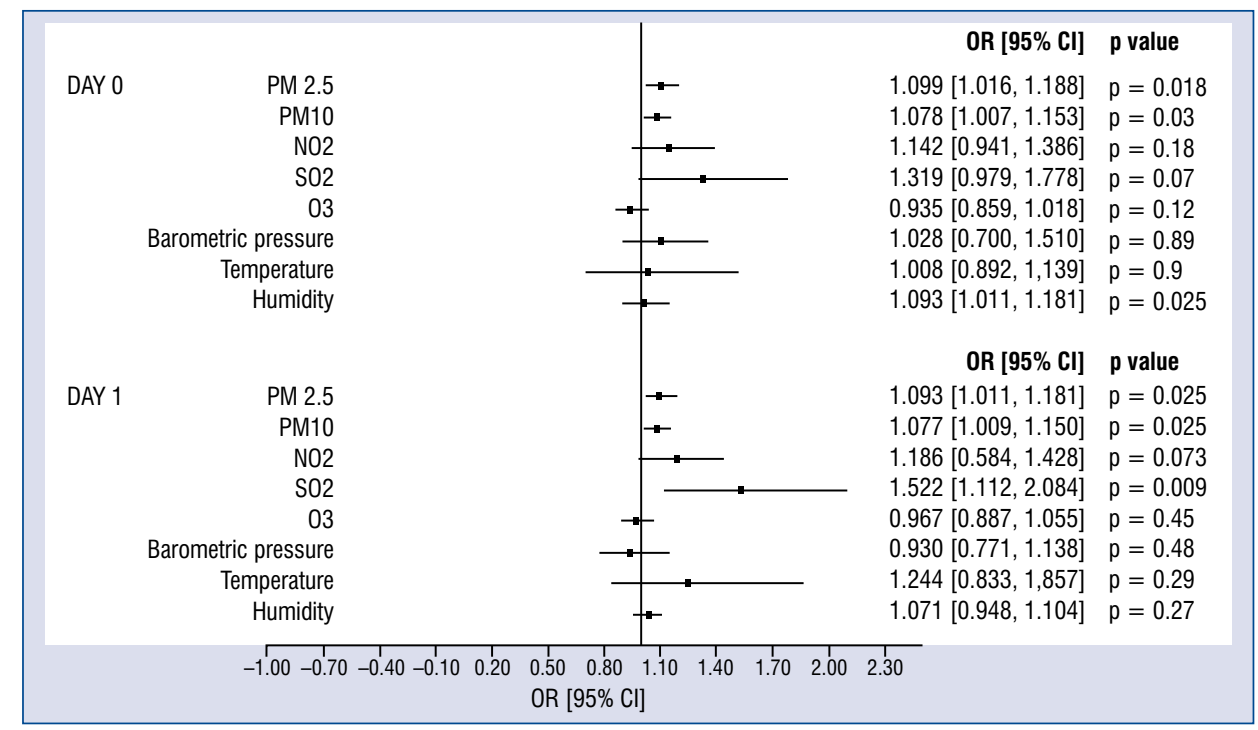

Figure 1. Logistic regression model for non-ST-segment elevation myocardial infarction (NSTEMI) occurrence; PM2.5 — particulate matter with diameter $<2.5 \mu \mathrm{m}$; PM10 — particulate matter with diameter $<10 \mu \mathrm{m}$; SO2 — sulfur dioxide; $\mathrm{NO} 2$ - nitrogen dioxide; $\mathrm{O} 3$ - ozone; OR — odds ratio; $\mathrm{Cl}$ - confidence interval.

and PM10 $(\mathrm{R}=0.9)$ or PM10 and NO2 $(\mathrm{R}=0.71)$, respectively. The intermediate or negative correlations were for $\mathrm{O} 3$ and humidity $(\mathrm{R}=-0.64), \mathrm{SO} 2$ and temperature $(\mathrm{R}=-0.63), \mathrm{O} 3$ and nitrogen oxides $(\mathrm{R}=-0.63$ for $\mathrm{NO}$ and -0.6 for $\mathrm{NO} 2)$.

\section{NSTEMI}

In the main analysis, both particulate matters including PM2.5 and PM10 had significant influence on NSTEMI occurrence on the day of air pollution exposure $(\mathrm{OR}=1.099$, CI 1.016-1.188, $\mathrm{p}=0.018$ for PM2.5 and OR $=1.078$, CI 1.007$-1.153, \mathrm{p}=0.03$ for PM10). Moreover, during the following day after air pollution, the exposure that triggered NSTEMI occurrence included SO2 $(\mathrm{OR}=1.522, \mathrm{CI} 1.112-2.084, \mathrm{p}=0.009)$ and both types of particulate matters: PM2.5 $(\mathrm{OR}=1.093$, CI $1.011-1.181, \mathrm{p}=0.025), \mathrm{PM} 10(\mathrm{OR}=1.077$, CI 1.009-1.150, $\mathrm{p}=0.025)$. An extensive analysis for NSTEMI is presented in Figure 1.

\section{STEMI}

The most important triggers for STEMI occurrence on the day of air pollution were gaseous pollutants including SO2 (OR $=1.670, \mathrm{CI} 1.230-2.266$, $\mathrm{p}=0.001), \mathrm{NO} 2(\mathrm{OR}=1.287, \mathrm{CI} 1.061-1.562, \mathrm{p}=0.011)$ and both particulate matters: $\mathrm{PM} 2.5(\mathrm{OR}=1.197, \mathrm{CI}$ 1.094-1.311, $\mathrm{p}<0.001)$ and PM10 (OR = 1.163, CI $1.079-1.253, \mathrm{p}<0.001)$. Similar results were seen on the following day after exposure and included $\mathrm{SO} 2(\mathrm{OR}=1.550, \mathrm{CI} 1.140-2.108, \mathrm{p}=0.005), \mathrm{NO} 2$
$(\mathrm{OR}=1.265$, CI 1.041-1.538, $\mathrm{p}=0.018), \mathrm{PM} 2.5$ $(\mathrm{OR}=1.172$, CI 1.076-1.276, $\mathrm{p}<0.001)$ and PM10 $(\mathrm{OR}=1.131$, CI 1.053-1.215, $\mathrm{p}<0.001)$. Detailed results for STEMI are presented in the Figure 2.

None of the weather conditions including temperature, barometric pressure and humidity reached statistical significance regarding to both types of MI and time periods.

\section{Discussion}

According to the latest WHO report, Poland is the most air-polluted region among European Union countries [11]. At the beginning of 2017, measured concentrations of PM2.5 and PM10 in some regions of Poland reached over 30 times recommended limits. The values had never been observed thus far in past years. Interestingly, this deterioration in air quality coincided with almost , fourteen thousand additional deaths in Poland compared to demographic data from January to February years 2016 and 2017 (Table 6, Based on Polish Central Statistical Office data) [13].

Confirmation of this serious situation in selected Polish cities are recorded in maximum values of air pollutants in Table 1, where the guideline limits are exceeded by up to $1000 \%$. What is more, analyzing Table 3 , during tested period about $35 \%$ of these days were above the daily limit of PM2.5. In addition, there is a lack of sufficient governmental action over the last decades to limit gas and dust 


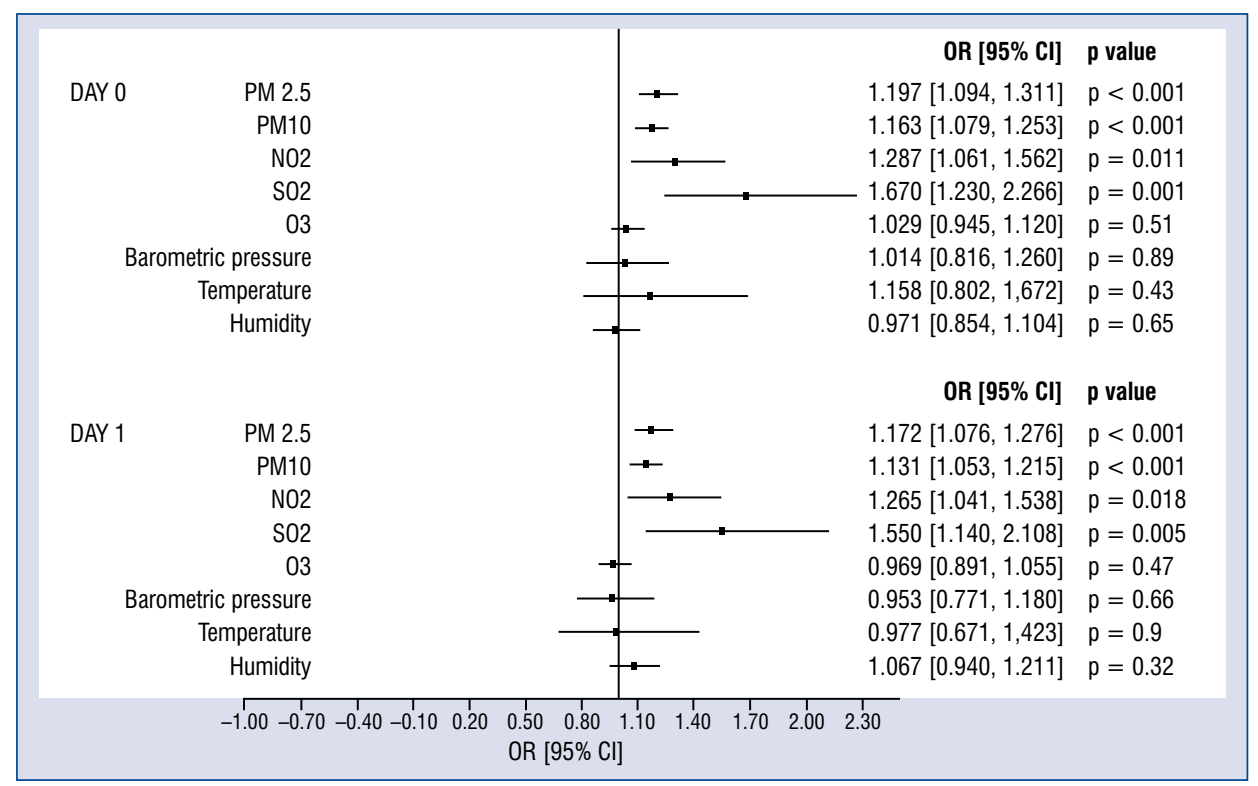

Figure 2. Logistic regression model for ST-segment elevation myocardial infarction (STEMI) occurrence; PM2.5 — particulate matter with diameter $<2.5 \mu \mathrm{m}$; PM10 - particulate matter with diameter $<10 \mu \mathrm{m}$; SO2 - sulfur dioxide; NO2 - nitrogen dioxide; $\mathrm{O} 3$ - ozone; OR - odds ratio; $\mathrm{Cl}$ - confidence interval.

Table 6. Differences in Polish population statistics [13].

\begin{tabular}{lccc}
\hline Month & 2016 & 2017 & $\begin{array}{c}\text { Change } \\
\text { in amount (\%) }\end{array}$ \\
\hline January & 33,000 & 44,400 & $+11,400(+35 \%)$ \\
February & 34,900 & 37,400 & $+2,500(+7 \%)$ \\
Total & 67,900 & 81,800 & $+13,900(+20.5 \%)$ \\
\hline
\end{tabular}

emissions, leading to systematic worsening of air pollution in Poland.

In the currently available literature, there remains a lack of studies examining the role of air pollution on MI occurrence in such polluted regions. In addition, only a few worldwide studies which have evaluated the influence of air pollution separately on NSTEMI and STEMI events. Most of the analyses were focused only on the impact of the particulate matters and overlooked the weather influence and gaseous pollutants. The present study takes into consideration a large number of air pollutants and weather conditions including: temperature, barometric pressure and humidity. It is also important to evaluate the influence of air pollution on AMI occurrence in the setting of a local environment. These features, as well as the number of variables and data taken into analysis from three different centers and cities make this study precise and plausible.
The present study found differences in the level of air pollution and its influence on each type of MI occurrence. These results have presented that the STEMI events are especially associated with particulate matters: PM10, PM2.5 and gaseous pollutants: SO2 and NO2. From particulate matters, the PM2.5 played the main role, which concurs with findings reported by other researchers [14]. Similar effects were seen during both examining days, which provides evidence that air pollution essentially has an impact on STEMI events. Comparable results of air pollution influence on STEMI occurrence were reported by other studies. Argacha et al. [15] found an association between STEMI and both particulate matters and NO2, which had the most significant impact, but SO2 was not included in this study. Pope et al. [16] in a large study, also found a similar association between STEMI and PM2.5 which was the only pollutant evaluated in the analysis.

On the other hand, weaker relationships were seen between air pollution and NSTEMI occurrence. Only particulate matter turn out to be statistically significant during the day of exposure to air pollution. The day after exposure, the importance in triggering NSTEMI had been reached by: PM10, PM2.5 and SO2. In the literature there are only a few studies showing evidence of air pollution influence on NSTEMI occurrence. This can be caused by the especially small number of studies 
exploring both types of AMI separately. Only the association between NSTEMI and daily maximum 1-h level of NO2 was confirmed by Butland et al. [17], but in this study the $\mathrm{SO} 2$ was not evaluated. Present findings regarding NSTEMI may also be caused by the high level of air pollution in Poland, which can exert significant influence on its appearance.

What is more, current results observed higher values of odds ratios for each $10 \mathrm{um} / \mathrm{m}^{3}$ increase in gaseous pollutants than PMs. This can be explained by a lower spread of its minimal and maximal levels, compared to other pollutants, mainly PM's. These findings confirm, that not only PMs play role in triggering MI, but the most dangerous for human health is a combination of gaseous pollutants, especially SO2 and NO2 with PMs, above PM2.5.

To summarize, the results of the current study clearly show that air pollution should be regarded as one of the modifiable risk factors of cardiovascular diseases that are the main cause of mortality in western countries and contribute to a serious economic burden with substantial loss of productivity and Gross Domestic Product value. Only coordinated governmental and local actions focused on air quality improvement in combination with an increase in health care expenditures may significantly improve the quality of life for patients, reduce total mortality rate, and positively influence the economy. Unfortunately, in many countries the problem remains underestimated causing a serious health threat. For instance, despite the fact that Poland is the most air-polluted region among European Union countries, the government instead of setting a priority for making air cleaner has recently and dangerously reduced expenditures on cardiology and the development of green energy production, putting patients at serious risk of increased mortality and morbidity.

\section{Limitations of the study}

The current study has some limitations. In a case-crossover design, the choice of a control period is crucial for results. A median value was taken of each variable for 7 days preceding MI occurrence. It seems to be the most neutral value, which can present the short-term changes in air quality and weather conditions. The study also has the same weakness, such as a lack of carbon monoxide levels, which theoretically can also impact MI occurrence.

\section{Conclusions}

The most important pollutants triggering STEMI and NSTEMI occurrence in three popula- tions of southern Poland, both on the day of air pollution and the following day are particular PM2.5 and PM10 matter and gaseous pollutants including $\mathrm{NO} 2$ and SO2. These pollutants should be regarded as modifiable risk factors and thus their reduction is a priority in order to decrease total morbidity and mortality.

\section{Conflict of interest: None declared}

\section{References}

1. World Health Organization, World Health Assembly closes, passing resolutions on air pollution and epilepsy. 2015.

2. World Health Organization, Ambient (outdoor) air quality and health. 2016.

3. Mustafić H, Jabre P, Caussin C, et al. Main air pollutants and myocardial infarction: a systematic review and meta-analysis. JAMA. 2012; 307(7): 713, doi: 10.1001/jama.2012.126.

4. Newby DE, Mannucci PM, Tell GS, et al. ESC Working Group on Thrombosis, Rehabilitation, E.S.C.H.F. Association.Expert position paper on air pollution and cardiovascular disease. Eur Heart J. 2015; 36(2): 83-93b.

5. Yin F, Lawal A, Ricks J, et al. Diesel exhaust induces systemic lipid peroxidation and development of dysfunctional pro-oxidant and pro-inflammatory high-density lipoprotein. Arterioscler Thromb Vasc Biol. 2013; 33(6): 1153-1161, doi: 10.1161/ATVBAHA.112.300552, indexed in Pubmed: 23559632.

6. Claeys MJ, Rajagopalan S, Nawrot RD. Brook, Climate and environmental triggers of acute myocardial infarction. Eur Heart J. 2017; 38(13): 955-960.

7. Kriszbacher I, Bodis J, Csoboth I, et al. The occurrence of acute myocardial infarction in relation to weather conditions. Int J Cardiol. 2009; 135(1): 136-138.

8. Bhaskaran K, Hajat S, Haines A, et al. Effects of ambient temperature on the incidence of myocardial infarction. Heart. 2009; 95(21): 1760-1769.

9. Houck P, Lethen J, Riggs M, et al. Relation of Atmospheric Pressure Changes and the Occurrences of Acute Myocardial Infarction and Stroke. Am J Cardiol. 2005; 96(1): 45-51, doi: 10.1016/j. amjcard.2005.02.042.

10. World Health Organization, World Health Statistics. 2017.

11. World Health Organization. 2016.

12. Maclure M. The case-crossover design: a method for studying transient effects on the risk of acute events. Am J Epidemiol. 1991; 133(2): 144-153.

13. Statistical Bulletin. 2017.

14. Cai X, Li Z, Scott EM. Short-term effects of atmospheric particulate matter on myocardial infarction: a cumulative meta-analysis. Environ Sci Pollut Res Int. 2016; 23(7): 6139-6148.

15. Argacha JF, Collart P, Wauters A, et al. Air pollution and ST-elevation myocardial infarction: A case-crossover study of the Belgian STEMI registry 2009-2013. Int J Cardiol. 2016; 223: 300-305, doi: 10.1016/j.ijcard.2016.07.191, indexed in Pubmed: 27541680.

16. Pope CA, Muhlestein JB, Anderson JL, et al. Short-Term Exposure to Fine Particulate Matter Air Pollution Is Preferentially Associated With the Risk of ST-Segment Elevation Acute Coronary Events. J Am Heart Assoc. 2015; 4(12), doi: 10.1161/ JAHA.115.002506, indexed in Pubmed: 26645834.

17. Butland BK, Atkinson RW, Milojevic Ai, et al. Myocardial infarction, ST-elevation and non-ST-elevation myocardial infarction and modelled daily pollution concentrations: a case-crossover analysis of MINAP data. Open Heart. 2016; 3(2): e000429, doi: 10.1136/ openhrt-2016-000429, indexed in Pubmed: 27621827. 